\title{
Solubility of Anthracene and Phenanthrene in Ethanol + 2,2,4-Trimethylpentane Mixtures at Different Temperatures
}

\author{
Ali Shayanfar, ${ }^{\dagger}$ Shadi H. Eghrary, ${ }^{\ddagger}$ Faroukh Sardari, ${ }^{\ddagger}$ William E. Acree, Jr., ${ }^{\S}$ and Abolghasem Jouyban ${ }^{*,+, \neq}$ \\ ${ }^{\dagger}$ Drug Applied Research Center and Faculty of Pharmacy, Tabriz University of Medical Sciences, Tabriz 51664, Iran \\ ${ }^{\ddagger}$ Division of Pharmaceutical Engineering, Department of Chemical Engineering, University of Tehran, Tehran, Iran \\ ${ }^{\S}$ Department of Chemistry, University of North Texas, Denton, Texas 76203-5070, United States
}

ABSTRACT: Solubility of anthracene and phenanthrene in binary mixtures of ethanol + 2,2,4-trimethylpentane at (298.2, 308.2, and 318.2) $\mathrm{K}$ are reported. Five numerical methods were used to predict the solubility of anthracene and phenanthrene in the studied binary solvent mixtures, and the mean relative deviation (MRD) was used as an error criterion. The MRD values for studied solvents are in acceptable range.

\section{INTRODUCTION}

Polycyclic aromatic hydrocarbons (PAHs) are among environmental pollutants with very low aqueous solubility values. Anthracene (with aqueous solubility of $0.0076 \mathrm{mg} \cdot \mathrm{L}^{-1}$ ) and phenanthrene (with aqueous solubility of $1.20 \mathrm{mg} \cdot \mathrm{L}^{-1}$ ) are among the most commonly found PAHs in the environment. ${ }^{1}$ Anthracene and phenanthrene are two isomeric forms of the simplest tricyclic aromatic hydrocarbon (Figure 1) and were used as model compounds in this work. Phenanthrene has lower molecular total energy, and it is more stable than anthracene according to $a b$ initio studies using molecular orbital method in the gas phase. ${ }^{2}$

Solubility alteration of chemicals is required in many industrial applications, and the solvent mixing or cosolvency is one of the most frequent and feasible methods used in the industry. Using different ratios of the solvents, a wide range of solubility for a given compound can be achieved. The next parameter which could be employed in the chemical industry is the changing temperature of the system which make a significant contribution in solubilization or crystallization of a compound. Finding an optimum solvent composition and the appropriate temperature in solubility investigations is usually obtained by trial and error which is both time-consuming and costly.

\section{SOLUBILITY MODELS}

Numerous predictive models have been introduced to replace the trial-and-error approach or at least reduce the number of required experimental data. ${ }^{1}$ One of these models, is the Jouyban-Acree model which correlates the solubility of a solute in binary solvent mixtures at various temperatures. ${ }^{3}$

$$
\ln X_{\mathrm{m}, T}^{\mathrm{Sat}}=x_{1} \cdot \ln X_{1, T}^{\mathrm{Sat}}+x_{2} \cdot \ln X_{2, T}^{\mathrm{Sat}}+\frac{x_{1} \cdot x_{2}}{T} \cdot \sum_{i=0}^{2} J_{i}\left(x_{1}-x_{2}\right)^{i}
$$

where $X_{\mathrm{m}, T}^{\mathrm{Sat}}$ is the solute mole fraction solubility in the mixed solvents at temperature $T ; x_{1}$ and $x_{2}$ are the mole fractions of solvents 1 and 2 in the absence of the solute; $X_{1, T}^{\mathrm{Sat}}$ and $X_{2, T}^{\mathrm{Sat}}$ denote the mole fraction solubility of the solute in monosolvents 1 and 2; and $J_{i}$ terms are the solvent - solvent and solute-solvent interaction coefficients. Our previous results showed that the model could be trained using the experimental data at $298.2 \mathrm{~K}$ and be used to predict the solubility at other temperatures of interest with acceptable error. ${ }^{4}$ These coefficients could also be computed using a minimum number of experimental solubility data in binary solvents and then be employed to predict solubility at other solvent compositions. To provide trained versions of the model to predict the solubility in binary solvents without employing solubility data in mixed solvents, a number of attempts were made. The binary interaction terms ( $J$ terms) have been correlated with the Hildebrand solubility parameters of the solvents and solutes. The reported quantitative structure property relationships (QSPR) using the Hildebrand solubility parameters are: ${ }^{5}$

$$
\begin{aligned}
& J_{0}=0.039\left(\delta_{1}-\delta_{\mathrm{s}}\right)+0.154\left(\delta_{2}-\delta_{\mathrm{s}}\right)+0.078\left(\delta_{1}-\delta_{\mathrm{s}}\right)^{2} \\
& -0.063\left(\delta_{2}-\delta_{s}\right)^{2} \\
& J_{1}=0.059\left(\delta_{1}-\delta_{\mathrm{s}}\right)+0.023\left(\delta_{2}-\delta_{\mathrm{s}}\right)+0.036\left(\delta_{1}-\delta_{\mathrm{s}}\right)^{2} \\
& -0.025\left(\delta_{2}-\delta_{s}\right)^{2} \\
& J_{2}=0.023\left(\delta_{1}-\delta_{\mathrm{s}}\right)-0.006\left(\delta_{2}-\delta_{\mathrm{s}}\right)+0.012\left(\delta_{1}-\delta_{\mathrm{s}}\right)^{2} \\
& -0.015\left(\delta_{2}-\delta_{s}\right)^{2}
\end{aligned}
$$

where $\delta_{1}, \delta_{2}$, and $\delta_{\mathrm{s}}$ represent the solubility parameter (expressed as $\left.\left(\mathrm{MPa}^{1 / 2}\right)\right)$ of solvent 1 , solvent 2 , and the solute, respectively. The numerical values for the solubility parameters of anthracene, phenanthrene, ethanol, and 2,2,4-trimethylpentane are 19.5, 19.9, 26.6, and 14.0, respectively.

In another attempt, the $J$ terms have been described using Abraham solvent and solute parameters. ${ }^{6}$ It is shown that these

Received: November 28, 2010

Accepted: February 8, 2011

Published: March 10, 2011 
(a)<smiles>c1ccc2cc3ccccc3cc2c1</smiles>

(b)

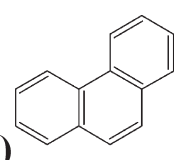

Figure 1. Structures of (a) anthracene and (b) phenanthrene.

models can be applied to obtain calculated solubility data in binary solvent mixtures with acceptable errors. ${ }^{6-9}$ The $J_{i}$ coefficients are described as

$$
\begin{aligned}
& J_{0}=0.028+2.123\left(c_{1}-c_{2}\right)^{2}-0.160 E\left(e_{1}-e_{2}\right)^{2} \\
& +0.282 S\left(s_{1}-s_{2}\right)^{2}+1.713 B\left(b_{1}-b_{2}\right)^{2}+2.006 V\left(v_{1}-v_{2}\right)^{2}
\end{aligned}
$$

$$
\begin{aligned}
& J_{1}=0.033+0.670\left(c_{1}-c_{2}\right)^{2}-0.477 E\left(e_{1}-e_{2}\right)^{2} \\
& +0.051 S\left(s_{1}-s_{2}\right)^{2}+0.476 B\left(b_{1}-b_{2}\right)^{2}+0.234 V\left(v_{1}-v_{2}\right)^{2}
\end{aligned}
$$

$$
\begin{gathered}
J_{2}=0.022+2.024\left(c_{1}-c_{2}\right)^{2}-0.204 E\left(e_{1}-e_{2}\right)^{2} \\
+0.034 S\left(s_{1}-s_{2}\right)^{2}+0.243 B\left(b_{1}-b_{2}\right)^{2}+0.848 V\left(v_{1}-v_{2}\right)^{2}
\end{gathered}
$$

for water-to-solvent Abraham solvent parameters, and

$$
\begin{aligned}
& J_{0}=0.062+0.118\left(c_{1}-c_{2}\right)^{2}-0.332 E\left(e_{1}-e_{2}\right)^{2} \\
+ & 0.410 S\left(s_{1}-s_{2}\right)^{2}+2.399 B\left(b_{1}-b_{2}\right)^{2}+15.715 L\left(l_{1}-l_{2}\right)^{2}
\end{aligned}
$$

$$
\begin{aligned}
& J_{1}=0.103+1.864\left(c_{1}-c_{2}\right)^{2}-1.590 E\left(e_{1}-e_{2}\right)^{2} \\
& +0.119 S\left(s_{1}-s_{2}\right)^{2}+1.010 B\left(b_{1}-b_{2}\right)^{2}-9.493 L\left(l_{1}-l_{2}\right)^{2}
\end{aligned}
$$

$$
\begin{aligned}
& J_{2}=0.008+1.075\left(c_{1}-c_{2}\right)^{2}-0.053 E\left(e_{1}-e_{2}\right)^{2} \\
& +0.084 S\left(s_{1}-s_{2}\right)^{2}+0.414 B\left(b_{1}-b_{2}\right)^{2}+7.727 L\left(l_{1}-l_{2}\right)^{2}
\end{aligned}
$$

for gas-to-solvent Abraham solvent parameters. In these equations, $c, e, s, b, v$, and $l$ are the Abraham solvent coefficients ${ }^{10}$ (Table 1); $E$ is the excess molar refraction, $S$ is the dipolarity/ polarizability, $B$ is the hydrogen bond basicity, $V$ is one percent of McGowan volume, and $L$ is the logarithm of gas-hexadecane partition coefficient of the solute at $298.15 \mathrm{~K}^{10}$

The solubilities of anthracene and phenanthrene in binary solvent mixtures have been extensively studied..$^{7-9,11,12}$ To the best of our knowledge, there is no reported solubility data for anthracene and phenanthrene in ethanol + 2,2,4-trimethylpentane mixtures in the literature. The aims of this study are: (1) The solubilities of anthracene and phenanthrene in ethanol $+2,2,4-$ trimethylpentane at $(298.2,308.2$, and 318.2) K are reported. (2) The constants of the Jouyban-Acree model for anthracene and phenanthrene in ethanol + 2,2,4-trimethylpentane mixtures are calculated. (3) The possibility of predicting the solubility of solutes at other temperatures using the trained model at $298.2 \mathrm{~K}$ is shown. (4) The Jouyban-Acree model combined with the Hildebrand solubility parameters is applied to predict the solubility of anthracene and phenanthrene in the binary solvent
Table 1. The Abraham Solvent Coefficients of Water and 2,2,4-Trimethylpentane $e^{10}$

\begin{tabular}{lccccccc}
\multicolumn{1}{c}{ water-to-solvent } & $c$ & $e$ & $s$ & $a$ & $b$ & $v$ \\
ethanol & 0.208 & 0.409 & -0.959 & 0.186 & -3.645 & 3.928 \\
2,2,4-trimethylpentane & 0.288 & 0.382 & -1.668 & -3.639 & -5.000 & 4.461 \\
$\quad$ & $c$ & $e$ & $s$ & $a$ & $b$ & $l$ \\
\multicolumn{1}{c}{ gas-to-solvent } & 0.012 & -0.206 & 0.789 & 3.635 & 1.311 & 0.853 \\
ethanol & 0.275 & -0.244 & 0.000 & 0.000 & 0.000 & 0.972 \\
\hline
\end{tabular}

mixtures at various temperatures. (5) The Jouyban-Acree model combined with Abraham parameters is applied to predict the solubility of solutes in the binary solvent mixtures at various temperatures. (6) The applicability of a new approach to predict the density of saturated solutions using the density of solute free solvent mixtures is also evaluated. ${ }^{13,14}$

\section{EXPERIMENTAL METHOD}

Materials. Anthracene (purity 0.96 in mass fraction) was purchased from Fluka, and it was recrystallized several times using 2-propanone and ethyl acetate to yield a purified sample having a melting point of $488 \mathrm{~K}$. Its purity was checked by a thin layer chromatography method, ${ }^{15}$ and also the measured solubilities in ethanol and 2,2,4-trimethylpentane were compared with the corresponding data from the literature. Phenanthrene (purity $>0.98$ in mass fraction) was purchased from Merck. It was recrystallized for several times using 2-propanone. A thin layer chromatography method ${ }^{15}$ and melting temperature determination equal to $372.15 \mathrm{~K}$ revealed its purity. Also, solubilities in ethanol and 2,2,4-trimethylpentane are in good agreement with previously published data. $8,10,16-18$ 2,2,4-Trimethylpentane (> 0.99 in mass fraction) and absolute ethanol $(>0.99$ in mass fraction) were purchased from Merck.

Apparatus and Procedures. The binary mixtures of ethanol + 2,2,4-trimethylpentane were prepared with appropriate mass fractions. The mole fractions of the solvents were computed with the uncertainty of 0.001 . The solubility of the analytes was determined by equilibrating excess amounts of the solids with the binary solvent mixtures using a shaker (Behdad, Tehran, Iran) placed in an incubator equipped with a temperature controlling system at $(298.2,308.2$, and 318.2) $\pm 0.2 \mathrm{~K}$ (Nabziran, Tabriz, Iran). For assurance of equilibrium, samples were incubated for three days at $298.2 \mathrm{~K}$. After solubility determination and density measurement at $298.2 \mathrm{~K}$, the remaining solutions containing excess solid were placed at $308.2 \mathrm{~K}$ for 1 day, and the measurements were carried out; the same procedure was repeated for $318.2 \mathrm{~K}$. The sample solutions were filtered using hydrophobic Durapore filters (0.4 5 $\mu \mathrm{m}$, Millipore, Ireland) and then were diluted using appropriate solvents (methanol for anthracene and 2-propanone for phenanthrene) for spectrophotometric analyses. Absorbances of the diluted solutions were recorded at $356 \mathrm{~nm}$ (for anthracene) and $345 \mathrm{~nm}$ (for phenanthrene) using a UV-vis spectrophotometer (Beckman DU-650, Fullerton, USA). Molar concentrations of the diluted solutions were determined from UV absorbance calibration graphs. The molar absorptivities of anthracene ranging from $\varepsilon=8177 \mathrm{~L} \cdot \mathrm{mol}^{-1} \cdot \mathrm{cm}^{-1}$ to $\varepsilon$ $=8199 \mathrm{~L} \cdot \mathrm{mol}^{-1} \cdot \mathrm{cm}^{-1}$ for compositions ranging from $0.000028 \mathrm{~mol} \cdot \mathrm{L}^{-1}$ to $0.000210 \mathrm{~mol} \cdot \mathrm{L}^{-1}$. The molar 
Table 2. Details of Different Numerical Methods Using the Jouyban-Acree Model Employed in This Study

\begin{tabular}{lll} 
method & \multicolumn{1}{c}{ J terms } & $\begin{array}{l}\text { solubilities in } \\
\text { monosolvent }\end{array}$ \\
I & $\begin{array}{l}\text { fitted parameters from eq } 1 \text { using } \\
\text { solubility data at each temperature }\end{array}$ & experimental \\
II & fitted parameters from eq 1 using & experimental \\
& solubility data at $298.2 \mathrm{~K}$ & \\
III & eqs 2 to 4 & experimental \\
IV & eqs 5 to 7 & experimental \\
V & eqs 8 to 10 & experimental \\
\hline
\end{tabular}

absorptivities of phenanthrene ranging from $\varepsilon=243 \mathrm{~L} \cdot \mathrm{mol}^{-}$ ${ }^{1} \cdot \mathrm{cm}^{-1}$ to $\varepsilon=224 \mathrm{~L} \cdot \mathrm{mol}^{-1} \cdot \mathrm{cm}^{-1}$ for compositions ranging from $0.002244 \mathrm{~mol} \cdot \mathrm{L}^{-1}$ to $0.005611 \mathrm{~mol} \cdot \mathrm{L}^{-1}$. Densities of the saturated solutions were determined using a $5 \mathrm{~mL}$ pycnometer.

\section{- CALCULATIONS}

Computing the Model Constants of Solutes in Ethanol + 2,2,4-Trimethylpentane. The generated experimental solubility data of anthracene and phenanthrene in ethanol +2,2,4-trimethylpentane at various temperatures were separately fitted to eq 1 , and the model constants were calculated by regressing (ln $\left.X_{\mathrm{m}, T}^{\mathrm{Sat}}-x_{1} \cdot \ln X_{1, T}^{\mathrm{Sat}}-x_{2} \cdot \ln X_{2, T}^{\mathrm{Sat}}\right)$ against $\left(\left(x_{1} \cdot x_{2}\right) / T\right),\left(\left(x_{1} \cdot x_{2}\right.\right.$ $\left.\left.\left(x_{1}-x_{2}\right)\right) / T\right)$, and $\left(\left(x_{1} \cdot x_{2}\left(x_{1}-x_{2}\right)^{2}\right) / T\right)$. Then the calculated solubility data were used to compute the mean relative deviations (MRD) as a criterion of error by

$$
\text { MRD }=\frac{1}{N} \sum\left[\frac{\left|\left(X_{\mathrm{m}}^{\text {Sat }}\right)_{\text {pred }}-\left(X_{\mathrm{m}}^{\text {Sat }}\right)_{\exp }\right|}{\left(X_{\mathrm{m}}^{\text {Sat }}\right)_{\text {exp }}}\right]
$$

in which $N$ is the number of data points in each set. This numerical analysis was called method I.

Predicting the Solubility of Solutes in Ethanol $+2,2,4-$ Trimethylpentane at (308.2 and 318.2) K. The generated experimental solubility data of anthracene and phenanthrene in ethanol + 2,2,4-trimethylpentane at $298.2 \mathrm{~K}$ were separately fitted to eq 1 , and the trained models were used to predict the solubility of solutes at (308.2 and 318.2) K, employing the solubility data in monosolvents at these temperatures. Then the MRDs for predicted data points were calculated using eq 11. This analysis is called method II.

Predicting the Solubility of Solutes in Ethanol $+2,2,4-$ Trimethylpentane at Various Temperatures Using Hildebrand Solubility Parameters. By using eqs 2 to $4, J_{i}$ terms of the Jouyban-Acree model for binary solvent mixtures were calculated. The obtained model was used to predict the solubility of solutes at (298.2, 308.2, and 318.2) K, employing the solubility data in monosolvents at these temperatures. Then the MRDs for predicted data points were calculated using eq 11 . This analysis is called method III.

Predicting the Solubility of Solutes in Ethanol $+2,2,4-$ Trimethylpentane at Various Temperatures Using Abraham Parameters. By using eqs 5 to $7, J_{i}$ terms of the Jouyban-Acree model for binary solvent mixtures were calculated. The trained model was used to predict the solubility of solutes at (298.2, 308.2 , and 318.2 ) K, employing the solubility data in monosolvents at these temperatures. Then the MRDs for predicted
Table 3. Solvent Composition (in Mole Fraction), Density $\rho$ of Saturated Solutions, and Experimental Mole Fraction Solubility of Anthracene $\left(10^{-5} X_{T, \exp }^{\text {Sat }}\right)$ and Phenanthrene $\left(X_{\mathrm{m}}^{\mathrm{Sat}}\right)$ in

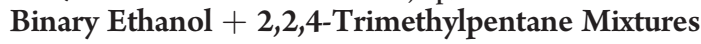

\begin{tabular}{|c|c|c|c|c|}
\hline $\begin{array}{c}\text { mole } \\
\text { fraction }\end{array}$ & $10^{-5} X_{T, \exp }^{\mathrm{Sat}}$ & density & $X_{T, \exp }^{\mathrm{Sat}}$ & density \\
\hline$x_{1}$ & $\overline{(\text { mole fraction) }}$ & $\overline{\rho\left(\mathrm{g} \cdot \mathrm{cm}^{-3}\right)}$ & $\overline{(\text { mole fraction) }}$ & $\rho\left(\mathrm{g} \cdot \mathrm{cm}^{-3}\right)$ \\
\hline \multicolumn{2}{|c|}{ Anthracene } & $T=298.2$ & \multicolumn{2}{|c|}{ Phenanthrene } \\
\hline 0.000 & 118.7 & 0.684 & 0.0246 & 0.693 \\
\hline 0.239 & 127.7 & 0.691 & 0.0272 & 0.705 \\
\hline 0.414 & 114.3 & 0.701 & 0.0266 & 0.718 \\
\hline 0.548 & 104.1 & 0.710 & 0.0239 & 0.726 \\
\hline 0.653 & 95.0 & 0.720 & 0.0220 & 0.738 \\
\hline 0.739 & 88.5 & 0.730 & 0.0213 & 0.746 \\
\hline 0.809 & 82.1 & 0.742 & 0.0196 & 0.757 \\
\hline 0.868 & 74.2 & 0.751 & 0.0171 & 0.767 \\
\hline 0.919 & 67.3 & 0.761 & 0.0149 & 0.777 \\
\hline 0.962 & 60.8 & 0.769 & 0.0134 & 0.787 \\
\hline 1.000 & 50.5 & 0.776 & 0.0119 & 0.793 \\
\hline \multicolumn{5}{|c|}{$T=308.2$} \\
\hline 0.000 & 151.5 & 0.679 & 0.0378 & 0.706 \\
\hline 0.242 & 161.0 & 0.687 & 0.0385 & 0.726 \\
\hline 0.418 & 146.6 & 0.697 & 0.0388 & 0.736 \\
\hline 0.552 & 135.9 & 0.706 & 0.0347 & 0.748 \\
\hline 0.657 & 124.4 & 0.716 & 0.0320 & 0.756 \\
\hline 0.742 & 116.0 & 0.726 & 0.0298 & 0.766 \\
\hline 0.812 & 105.9 & 0.736 & 0.0273 & 0.776 \\
\hline 0.870 & 95.9 & 0.746 & 0.0234 & 0.786 \\
\hline 0.920 & 86.2 & 0.755 & 0.0212 & 0.796 \\
\hline 0.963 & 77.7 & 0.765 & 0.0181 & 0.806 \\
\hline 1.000 & 66.5 & 0.777 & 0.0159 & 0.812 \\
\hline \multicolumn{5}{|c|}{$T=318.2$} \\
\hline 0.000 & 176.8 & 0.679 & 0.0484 & 0.720 \\
\hline 0.240 & 189.8 & 0.687 & 0.0510 & 0.734 \\
\hline 0.415 & 170.5 & 0.697 & 0.0473 & 0.744 \\
\hline 0.549 & 154.8 & 0.706 & 0.0421 & 0.758 \\
\hline 0.654 & 140.4 & 0.716 & 0.0384 & 0.768 \\
\hline 0.739 & 129.5 & 0.726 & 0.0358 & 0.778 \\
\hline 0.810 & 121.4 & 0.736 & 0.0322 & 0.792 \\
\hline 0.869 & 108.7 & 0.746 & 0.0282 & 0.796 \\
\hline 0.919 & 97.9 & 0.755 & 0.0254 & 0.812 \\
\hline 0.962 & 88.4 & 0.767 & 0.0227 & 0.814 \\
\hline 1.000 & 78.0 & 0.775 & 0.0190 & 0.816 \\
\hline
\end{tabular}

data points were calculated using eq 11 . This analysis is called method IV. Similar procedures could be used to develop a predictive method employing the experimental data in monosolvents and $J$ terms calculated using eqs 8 to 10 (method V). The Abraham solute parameters for anthracene are $E=2.290, S=$ 1.34, $B=0.280, V=1.4540$, and $L=7.568$, and those of phenanthrene are $E=2.055, S=1.29, B=0.29, V=1.4544$, and $L=7.632 .^{11}$ A summary of methods I to $\mathrm{V}$ is listed in Table 2.

Predicting the Density of Saturated Solutions at Various Temperatures Using a Trained Model for Ethanol + 2,2,4- 
Table 4. Solubility of Anthracene and Phenanthrene in Ethanol and 2,2,4-Trimethylpentane at 298.2 K Taken from the Literature and the Generated Data in This Work

\begin{tabular}{|c|c|c|c|c|c|c|}
\hline solute & solvent & solubility (unit) & reference & solubility (unit) & reference & difference \% \\
\hline anthracene & ethanol & $0.0078\left(\mathrm{~mol} \cdot \mathrm{L}^{-1}\right)$ & 10 & $0.0085\left(\mathrm{~mol} \cdot \mathrm{L}^{-1}\right)$ & this work & -8.2 \\
\hline anthracene & ethanol & $0.0087\left(\mathrm{~mol} \cdot \mathrm{L}^{-1}\right)$ & 16 & $0.0085\left(\mathrm{~mol} \cdot \mathrm{L}^{-1}\right)$ & this work & 2.4 \\
\hline anthracene & 2,2,4-trimethylpentane & $0.0066\left(\mathrm{~mol} \cdot \mathrm{L}^{-1}\right)$ & 10 & $0.0071\left(\mathrm{~mol} \cdot \mathrm{L}^{-1}\right)$ & this work & -7.0 \\
\hline anthracene & 2,2,4-trimethylpentane & $0.0067\left(\mathrm{~mol} \cdot \mathrm{L}^{-1}\right)$ & 16 & $0.0071\left(\mathrm{~mol} \cdot \mathrm{L}^{-1}\right)$ & this work & -5.6 \\
\hline phenanthrene & ethanol & 0.0128 (mole fraction) & 17 & 0.0119 (mole fraction) & this work & 7.6 \\
\hline phenanthrene & ethanol & 0.0111 (mole fraction) & 18 & 0.0119 (mole fraction) & this work & -6.7 \\
\hline phenanthrene & ethanol & 0.0111 (mole fraction) & 8 & 0.0119 (mole fraction) & this work & -6.7 \\
\hline
\end{tabular}

Table 5. The Jouyban-Acree Model Constants Calculated for Studied Solutes in Ethanol + 2,2,4-Trimethylpentane Solvent Mixtures

\begin{tabular}{lccc}
\multicolumn{1}{c}{ solute } & $J_{0}$ & $J_{1}$ & $J_{2}$ \\
anthracene & 382.630 & 86.985 & 432.112 \\
phenanthrene & 456.829 & 171.041 & 307.215 \\
\hline
\end{tabular}

Table 6. The Mean Relative Deviation (MRD) for Numerical Methods I to $\mathrm{V}$ for Predicting Solubility of Anthracene and Phenanthrene in Ethanol + 2,2,4-Trimethylpentane Mixtures

\begin{tabular}{lccccc}
\multicolumn{1}{c}{ solute } & I & II & III & IV & V \\
anthracene & 1.1 & 1.4 & 11.8 & 6.8 & 27.6 \\
phenanthrene & 1.5 & 1.9 & 14.2 & 4.4 & 24.6 \\
\hline
\end{tabular}

Trimethylpentane Mixtures. By using the solute free density data of ethanol $+2,2,4$-trimethylpentane mixtures at various temperatures, the Jouyban-Acree model could be trained as ${ }^{13}$

$$
\begin{gathered}
\ln \rho_{\mathrm{m}, T}=x_{1} \ln \rho_{1, T}+x_{2} \ln \rho_{2, T} \\
-49.137\left(\frac{x_{1} x_{2}}{T}\right)+12.03\left(\frac{x_{1} x_{2}\left(x_{1}-x_{2}\right)}{T}\right)
\end{gathered}
$$

in which $\rho_{\mathrm{m}, T}$ is the density of mixed solvent system in the absence of a solute and $\rho_{1, T}$ and $\rho_{2, T}$ are the density of monosolvents 1 and 2 in the absence of a solute at temperature of $T$. This model was used to predict the density of saturated solutions at various temperatures.

\section{RESULTS AND DISCUSSION}

Mole fraction compositions of the binary solvent mixtures, solubilities of anthracene and phenanthrene, densities of the solute free mixed solvents, and the density of saturated solutions at different temperatures are reported in Table 3. Each experimental data point is an average of at least three experimental measurements with the measured $\mathrm{mol} \cdot \mathrm{L}^{-1}$ solubilities being reproducible to within $\pm 2.7 \%$ and $2.5 \%$ and standard deviations ranging from $\left(\sigma_{n-1}=0.00065\right.$ to $\left.\sigma_{n-1}=0.00010\right) \mathrm{mol} \cdot \mathrm{L}^{-1}$ and from $\left(\sigma_{n-1}=0.0002\right.$ to $\left.\sigma_{n-1}=0.0250\right) \mathrm{mol} \cdot \mathrm{L}^{-1}$, respectively, for anthracene and phenanthrene. The reported solubility data of the solutes from the literature are listed in Table 4. There are good agreements between generated solubility data in this work with those from the literature. The $J_{i}$ terms of the JouybanAcree model for studied solutes in ethanol + 2,2,4-trimethylpentane solvent mixtures were calculated using a no-intercept regression analysis and are listed in Table 5. The MRD values for the predicted solubility using different numerical methods

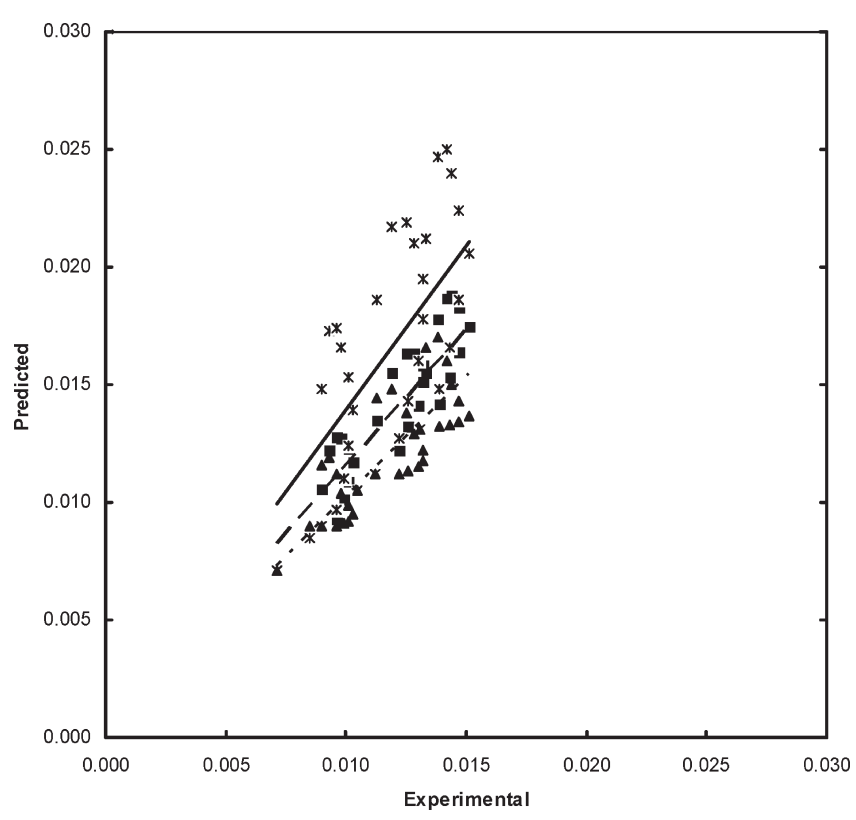

Figure 2. Predicted solubility of anthracene using different numerical analyses versus experimental values; method III, $\mathbf{\Delta}$, - - -; method IV, $\mathbf{\square},--$; and method $\mathrm{V}, *,-$.

for anthracene and phenanthrene were tabulated in Table 6. The results showed that the Jouyban-Acree model is well fitted to the generated data with MRD values of $1.1 \%$ and $1.5 \%$, respectively, for anthracene and phenanthrene (method I). The trained model using solubility data at a constant temperature (i. e., $298.2 \mathrm{~K})$ can be used to predict the solubility at other temperatures $((308.2$ and 318.2$) \mathrm{K})$ in which the MRD values of $1.4 \%$ and $1.9 \%$ were obtained for anthracene and phenanthrene. The solubility prediction capability of anthracene and phenanthrene at different temperatures using previous trained models at constant temperatures (methods III to V) are 11.8, 6.8, 27.6 , and 14.2, 4.4, and 24.6, respectively. Figure 2 illustrated the predicted solubility of anthracene in ethanol $+2,2,4$-trimethylpentane at different temperatures using methods III to V. The correlation coefficients of methods III to V are $0.7773,0.7949$, and 0.7078 , respectively. The closer correlation coefficient to 1.0000 means more accurate predicted solubilities by the method, and concerning this, method IV provided the best predictions followed by methods III and V. The slope of the no-intercept linear equation between predicted and experimental values could be considered as another criterion. The slopes for methods III, IV, and V are 1.0211, 1.1548, and 1.3967, respectively, in which the ideal value for the slope is 1.0000 . Considering this criterion, prediction performance of the method III is better than method 


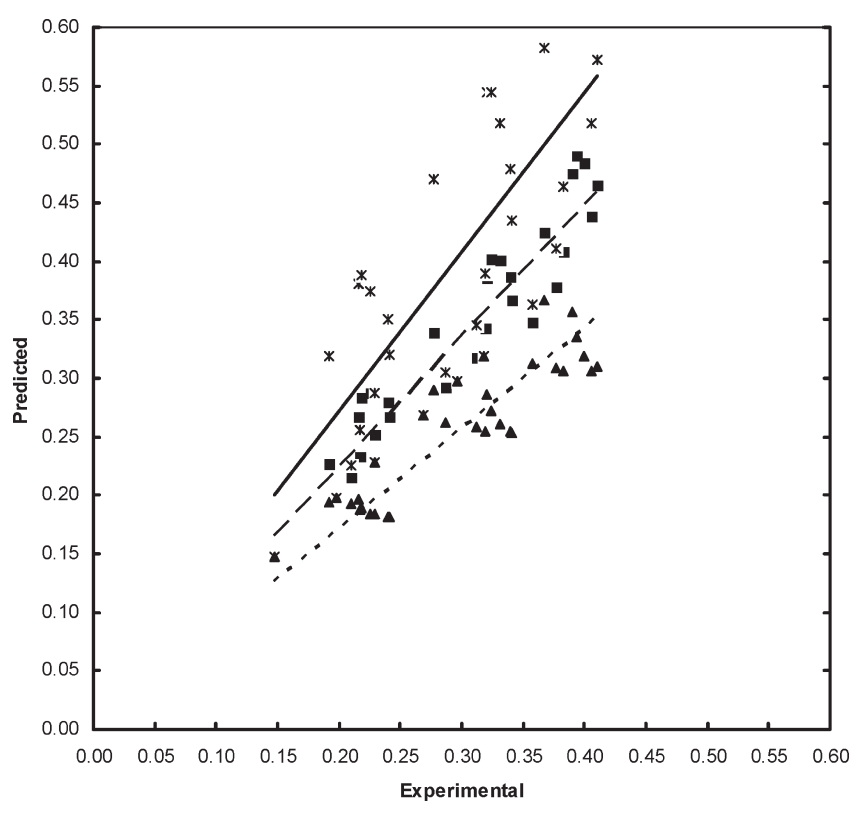

Figure 3. Predicted solubility of phenanthrene using different numerical analyses versus experimental values; method III, $\mathbf{\Lambda}$, - - -; method IV, $\mathbf{\square},--$; and method $\mathrm{V}, *,-$.

IV, followed by method V. A similar plot for phenanthrene data was shown in Figure 3, in which the correlation coefficients for methods III, IV, and V are 0.8800, 0.9465, and 0.8076, respectively. The corresponding slopes are $0.8572,1.1184$, and 1.3620 . These findings are in agreement with the MRD values reported in Table 6 . These results show that trained model using water to solvent Abraham coefficient (method IV) provide more accurate predictions for the reported solubility data in this study.

The densities of the solute saturated solution were predicted using eq 12 and experimental $\rho_{1, T}$ and $\rho_{2, T}$ of the saturated solutions. The results show that MRD values of eq 12 for predicting densities of anthracene and phenanthrene in ethanol + 2,2,4-trimethylpentane mixtures at various temperatures are $0.5 \%$ and $0.9 \%$, respectively.

As a conclusion, the solubility prediction of drugs and chemical compounds such as PAHs in solvent mixtures at different temperatures is very important in chemical and pharmaceutical sciences. Solubilities of two PAHs were reported in a binary solvent mixture at various temperatures, and the results of the numerical analyses revealed that previous QSPR models can be extended to solubility prediction at different temperatures.

\section{AUTHOR INFORMATION}

\section{Corresponding Author}

*E-mail: ajouyban@hotmail.com and jouyban@ut.ac.ir. Fax: +984113363231.

\section{Funding Sources}

The authors would like to thank the Drug Applied Research Center for the partial financial support under Grant No. 85-83.

\section{ACKNOWLEDGMENT}

The authors would like to thank Prof. Sotudeh-Gharebagh and Dr Zarghami from Tehran University for reviewing the manuscript and their useful comments.

\section{REFERENCES}

(1) Pazos, M.; Rosales, E.; Alcántara, T.; Gómez, J.; Sanromán, M. A. Decontamination of Soils Containing PAHs by Electroremediation: A Review. J. Hazard. Mater. 2010, 177, 1-11.

(2) Gong, X. D.; Xiao, H. M. Ab initio studies on the structures and thermodynamic functions of phenanthrene and anthracene. J. Phys. Org. Chem. 1999, 12, 441-446.

(3) Jouyban, A. Handbook of Solubility Data for Pharmaceuticals; CRC Press, Taylor \& Francis Group: Boca Raton, FL, 2009.

(4) Jouyban, A.; Shayanfar, A.; Acree, W. E., Jr. Solubility Prediction of Polycyclic Aromatic Hydrocarbon in Non-aqueous solvent mixtures. Fluid Phase Equilib. 2010, 293, 47-58.

(5) Jouyban, A.; Khoubnasabjafari, M.; Chan, H.-K.; Clark, B. J.; Acree, W. E., Jr. Solubility prediction of anthracene in mixed solvents using a minimum number of experimental data. Chem. Pharm. Bull. 2002, 50, 21-25.

(6) Jouyban, A.; Acree, W. E., Jr. Solubility Prediction in NonAqueous Binary Solvents Using a Combination of Jouyban-Acree and Abraham Models. Fluid Phase Equilib. 2006, 249, $24-32$.

(7) Shayanfar, A.; Soltani, S.; Jabbaribar, F.; Hamidi, A. A.; Acree, W. E., Jr.; Jouyban, A. Naphthalene Solubility in Binary Solvent Mixtures of 2,2,4-Trimethylpentane + Alcohols at 298.15 K. J. Chem. Eng. Data 2008, 53, 574-577.

(8) Fakhree, M. A. A.; Shayanfar, A.; Acree, W. E., Jr.; Jouyban, A. Solubility of Phenanthrene in Binary Mixtures of $\mathrm{C}_{1}-\mathrm{C}_{4}$ Alcohols + 2-Propanol and Ethanol + Methanol at 298.2 K. J. Chem. Eng. Data 2009, 54, 1405-1408.

(9) Jouyban, A.; Manzoori, J. L.; Soleymani, J.; Panahi-Azar, V.; Fakhree, M. A. A.; Ahmadian, S.; Shayanfar, A.; Acree, W. E. Solubility of Anthracene in $\mathrm{C}_{1}-\mathrm{C}_{3}$ Alcohols from (298.2 to 333.2) $\mathrm{K}$ and Their Mixtures with 2-Propanone at 298.2 K. J. Chem. Eng. Data 2010, 55, 5319-5322.

(10) Acree, W. E., Jr.; Abraham, M. H. Solubility Predictions for Crystalline Nonelectrolyte Solutes Dissolved in Organic Solvents Based Upon the Abraham General Solvation Model. Can. J. Chem. 2001, 79, 1466-1476.

(11) Ali, S. H.; Al-Mutairi, F. S.; Fahim, M. A. Solubility of Polycyclic Aromatics in Binary Solvent Mixtures Using Activity Coefficient Models. Fluid Phase Equilib. 2005, 230, 176-183.

(12) Alcazar, L.; Blanco, A.; Cano, R; Fisher, L.; Nau, M.; Sidransky, L.; Acree, W. E., Jr. Solubility of Anthracene in Binary Propyl Acetate + Alcohol Solvent Mixtures at 298.15 K. J. Chem. Eng. Data 2008, 53, 201-203.

(13) Jouyban, A.; Fathi-Azarbayjani, A.; Khoubnasabjafari, M.; Acree, W. E., Jr. Mathematical Representation of the Density of Liquid Mixtures at Various Temperatures Using Jouyban-Acree Model. Indian J. Chem. A 2005, 44, 1553-1560.

(14) Soltanpour, S.; Jouyban, A. Solubility of Acetaminophen and Ibuprofen in Binary and Ternary Mixtures of Polyethylene Glycol 600, Ethanol and Water. Chem. Pharm. Bull. 2010, 50, 219-224.

(15) Loncar, E. S.; Kolarov, L. A.; Malbasa, R. V.; Skrbic, B. D. Qualitative TLC Determination of Some Polycyclic Aromatic Hydrocarbons in Sugar-Beet. J. Serb. Chem. Soc. 2005, 70, 1237-1242.

(16) Shayanfar, A.; Soltani, S.; Jabbaribar, F.; Tamizi, E.; Acree, W. E., Jr.; Jouyban, A. Solubility of Anthracene in Ternary Solvent Mixtures of 2,2,4-Trimethylpentane + 2-Propanone + Alcohols at 298.15 K. J. Chem. Eng. Data 2008, 53, 890-893.

(17) Draucker, L. C.; Janakat, M.; Lazzaroni, M. J.; Bush, D.; Eckert, C. A.; Frank, T. C.; Olson, J. D. Experimental Determination and Model Prediction of Solid Solubility of Multifunctional Compounds in Pure and Mixed Nonelectrolyte Solvents. Ind. Eng. Chem. Res. 2007, 46, 2198-2204.

(18) Hernandez, C. E.; De Fina, K. M.; Roy, L. E.; Sharp, T. L.; Acree, W. E., Jr.; Abraham, M. H. Solubility of Phenanthrene in Organic Nonelectrolyte Solvents. Comparison of Observed versus Predicted Values Based Upon Mobile Order Theory. Can. J. Chem. 1999, 77, 1465-1470. 